\title{
THE MOBILIZING POWER OF GRIEVANCES: APPLYING LOSS AVERSION AND OMISSION BIAS TO SOCIAL MOVEMENTS"
}

\author{
Kelly Bergstrand
}

\begin{abstract}
This study investigates how the nature of grievances can provide advantages or disadvantages to social movements. I use an experimental design to test the effects of loss aversion and omission bias on people's reactions toward grievances and the campaigns that seek to address them. The results indicate that grievances involving a loss are perceived as more immoral, unjust, and important than grievances involving a gain. Loss-based grievances also generate stronger emotions, increase willingness to engage in activism, and produce perceptions of greater public support. Similarly, grievances resulting from a commission (action), as compared to an omission (inaction), are seen as more immoral, unjust, and important. Commission-based grievances direct attribution of blame toward perpetrators, evoke higher levels of emotions, and increase willingness to participate in campaigns. These findings provide support for the idea that not all grievances are created equal in their ability to appeal to and potentially mobilize the public.
\end{abstract}

While early theorists emphasized strain in society as a determinant of social movement activity, few modern studies have endeavored to understand the role of grievances in drawing sympathy and support for movements. Other areas of inquiry, such as work on emotions in social movements (Goodwin, Jasper, and Polletta 2001; Jasper 1998; Nepstad and Smith 2001), have demonstrated the usefulness of reexamining ideas that were initially investigated over fifty years ago. Grievances also are likely to differ in their ability to attract attention and support, and it is worthwhile to explore how the content of grievances can motivate sympathy and action for causes. Indeed, the likelihood of participation in collective action depends, at least in part, on how compelling people find the issue to be.

Thus, in mapping mobilization processes, it is of interest to study the possible effects that a movement's grievance has on attitudes toward and support for the movement. Whether or not individuals actually participate in a social movement, or if a movement is able to achieve its desired outcomes, ultimately depends on a multitude of factors, such as the movement's resources and the larger political context. The nature of the grievance could be another important variable to take into consideration when attempting to understand movement recruitment and strength.

This study focuses systematically on ways that grievances might matter. The popularity of any particular topic is likely to rise and fall, reflecting fads in public opinion as well as the influence of current events. Are there strengths and weaknesses of issues that exist in relatively durable ways? Can such strengths and weaknesses be identified across different movement types, geographies, and even historical eras? ${ }^{1}$ To answer these questions, I turn to work in psychology and behavioral economics that has identified concepts that tend to

\footnotetext{
*I would like to thank Kraig Beyerlein, Linda Molm, Erin Leahey and Mobilization's anonymous reviewers for their helpful comments on earlier drafts of this article. A grant from the National Science Foundation helped support this research (award number 1102555).

${ }^{\dagger}$ Kelly Bergstrand is a Ph.D. candidate in the Department of Sociology at the University of Arizona. Please direct all correspondence to Kelly Bergstrand, School of Sociology, University of Arizona, P.O. Box 210027, Tucson, AZ 85721, or via email at kellyjb@email.arizona.edu.

(C) 2014 Mobilization: An International Quarterly 19(2): 123-142
} 
provoke systematic, predictable responses. I investigate whether these ideas can be applied to social movements to develop theory about the mobilization effects of grievances.

Specifically, I utilize cognitive biases - which are when individuals draw inferences or adopt beliefs where the evidence for doing so in a logically sound manner is either insufficient or absent (Haselton, Nettle, and Andrews 2005: 725). I examine the effects of two biases in judgment and decision making on social movement campaigns: loss aversion and omission bias. Loss aversion states that people find losses more aversive than they find comparable gains attractive, with individuals taking greater risks to avoid losses than to acquire gains (Kahneman and Tversky 1979; Tversky and Kahneman 1981). Loss aversion can be considered a bias to the extent that it results in differential preferences for logically equivalent outcomes and may go against what rationality suggests are more optimal decisions (Arceneaux 2012). From a social movement perspective, such losses could take a variety of forms, from threats to jobs to waning political power.

Omission bias is a preference for harms caused by omissions over equal or lesser harms caused by actions (Baron and Ritov 2004). People have a tendency to view commissions as more immoral, more punishable, and more causal than similar omissions (Spranca, Minsk, and Baron 1991; Sugarman 1986). An example of this is found in human euthanasia, where orders to not resuscitate are less controversial than assisted suicide. Both loss aversion and omission bias elicit effects that make them particularly applicable to mobilization processes, such as greater risk taking in response to losses and clearer attribution of blame for acts of commission.

I assess whether issues that trigger the positive and negative dimensions of these biases (e.g., loss versus gain and commission versus omission) have differential effects on movement sympathy and willingness to participate in collective action. To do so, I use vignette studies, each of which describes a grievance as well as the social movement campaign that seeks to address it. The vignettes are identical except for language pertaining to the different dimensions of the bias embedded in the grievance (e.g., loss-based grievance or gain-based grievance; commission-based grievance or omission-based grievance). I then ask a series of questions that investigate how these differences in grievances affect attitudes about the grievance, emotional reactions, perceptions of broader support, beliefs about campaign success, and willingness to participate in campaigns to redress the grievance. The results of this study support the idea that the nature of grievances matter for both garnering sympathetic support as well as spurring individuals to consider acts of activism.

\section{SOCIAL MOVEMENT GRIEVANCES: THREATS, MORAL SHOCKS, AND FRAMING}

While social movement literature is largely silent on how the nature of grievances affects mobilization, there are some notable exceptions. This includes work done on threats motivating collective action in reactive social movements and the ability of sudden or shocking grievances to provoke activism. Additionally, research on framing strategies can be applied to grievances to suggest ways grievances may aid or hinder collective action.

One area of inquiry in social movements refers to how grievances in the form of threats and strain can encourage collective action. This body of work was particularly popular in the mid-twentieth century and posited that people turned to collective action when confronted with structural strains and rapid social changes (Kornhauser 1959; Smelser 1962). Strain theory has since been widely and justifiably critiqued for many of its misconceptions (McCarthy and Zald 1977). However, modern studies have found support for ideas rooted in strain theory: that structural changes and social disruptions, particularly those viewed as a threat, can foster collective action. Van Dyke and Soule (2002) found that threats produced by structural social changes, such as a decline in manufacturing jobs and the family farm, increased mobilization in patriot/militia movements. Snow et al. (1998), in a modern appli- 
cation of breakdown theory, investigated how actual or threatened disruptions to the quotidian - the routines and attitudes of daily life - encouraged collective action. Tilly $(1976,1978)$ examined reactive collective action, where groups attempted to reassert established claims that had been challenged, with relevant historical cases including food riots, tax rebellions, and movements against military conscription. McVeigh (1999) found that in the 1920s, power devaluation in both economic and political arenas for native-born, white Protestants provided an opportunity for the Ku Klux Klan to craft cultural appeals that would restore power for this group and successfully contributed to an expansion in Klan membership. In these studies, grievances again become a focal interest in understanding what motivates participation in social movements. McVeigh (1999: 1463) offers support for this idea when he writes that for conservative movements, it is not the infusion of external resources or expanding opportunities that provide the initial incentive for collective action. Rather it is the emergence of new grievances.

While threats constitute one way the nature of grievances can encourage mobilization, another route is that sudden or shocking grievances propel individuals into action. Unexpected, alarming events such as the Three Mile Island nuclear reactor accident can act as an example where suddenly imposed major grievances have been important in explaining grass roots mobilization (Walsh 1981: 17). Similarly, moral shocks occur when an event or piece of information outrages or upsets someone such that he or she becomes inclined toward political action, even in the absence of active recruitment (Jasper 1997: 106). For instance, Luker (1984) found that many anti-abortion activists were self-recruits; they independently encountered and were distressed by information on abortion and then actively sought out a political group that shared their values. These cases illustrate the ability of sudden or powerful grievances to trigger outrage and ultimately action.

Additionally, work on framing speaks to the ways that grievances might be more or less able to appeal to the public. Social movement actors can use framing strategies to help achieve movement objectives, such as acquiring resources and recruiting participants (Benford and Snow 2000; Snow and Benford 1988). Some frames are more effective than others, such as those that resonate with the public or offer clear diagnoses of problems and prognostics for solutions (Snow and Benford 1988). Similarly, some grievances are likely to lend themselves to easier diagnoses and prognostics than others. For instance, small-scale, single-issue campaigns may have clearer targets and cleaner recipes for success than larger, global problems, like racism or global warming, which entail complex webs of causes and solutions. Javeline (2003) notes that workers are some of the most frequent protesters since problems and solutions usually reside in a known target - the employer. Further, movements on topics that are more technical or abstract may struggle to resonate with everyday people, such as movements that seek to reform global currency speculation. In this manner, work on framing can signal ways that underlying grievances may help or hinder the development of frames to facilitate mobilization.

In turn, identifying how grievances appeal to the public contributes to an understanding of effective framing strategies. This study finds that losses and direct actions give movements an advantage in garnering support. This information could be used to develop stronger campaign frames for movements addressing issues that have flexibility in whether they can be couched as gains or losses, or as commissions or omissions. However, there is the caveat that some social movements may not be able to adjust their frames so readily and remain true to the issue. As Benford and Snow (2000: 625) state, "activists are not able to construct and impose on their intended targets any version of reality they would like." If a campaign seeks a gain - such as a new community center-it is likely they will struggle more to frame this as a loss than a similar campaign that is defending a community center from threats to tear it down. Social movement actors may have to pour more time, energy, and resources into framing an issue when the raw material of the grievance does not naturally reflect the desired frame. Additionally, such a discrepancy between the frames and the grievance could make the 
movement more vulnerable to counterframes from other actors - such as countermovements, the media, or elites - who may seize the opportunity to undermine the social movement's claims. Thus, understanding strengths and weaknesses of grievances can be useful for framing, but the content of grievances may constrain the extent to which social movement actors can take advantage of this knowledge.

A similar problem is found in framing strategies that attempt to mitigate the challenges of motivating and achieving collective action, such as those related to social dilemmas. Social dilemmas are situations in which behavior that is reasonable for individuals leads to a situation in which everyone ends up being worse off (for a review, see Kollock 1998). Classic difficulties in collective action include freeriding in the production of, as well as the unsustainable consumption of, public goods (e.g., Hardin 1968; Olson 1965). Social movement organizers can attempt to overcome tendencies like freeriding in their calls to action; however, this can be a challenge, potentially leading to counterproductive outcomes (Vasi and Macy 2003). Just as social movement organizers may need to contend with difficulties stemming from problems associated with collective action, they may also be limited by the nature of the grievance itself.

\section{THE EFFECTS OF GRIEVANCES: THE BALCONY AND THE BARRICADE}

People are likely to differ in their reactions to grievances, from the person who forms an opinion about an issue but is not willing to take any further action, to the committed activist willing to devote significant time and resources to the cause. Thus, to gain a complete portrait of the mobilizing effects of grievances, I assess the impact of grievance content on both attitudes toward the issue as well as willingness to engage in acts of activism.

Some grievances may be more effective than others in drawing people to sympathize with the issue, which in turn may lead to participation in acts like protest. Those who have favorable views of a movement are more likely to be part of the mobilization potential - the reservoir of people who could be mobilized by a social movement, which includes people who have positive attitudes toward the movement's goals and are willing to participate in unconventional political action such as protest (Klandermans and Oegema 1987). Therefore, understanding how the content of grievances augments, or diminishes, positive attitudes toward a campaign is relevant for discerning how the mobilization potential is formed - the first step in a process that may lead to participation in a movement.

People's attitudes also matter as an end in itself, independent of whether individuals are personally willing to engage in movement activities. Social movements may prize attitudinal transformations as a goal; some gay rights campaigns, for example, have sought "to improve the image of homosexuals in the eye of the American public" (Fetner 2001: 419). The court of public opinion can be equally relevant for social movements that seek to accomplish policyoriented objectives. In an analysis of existing literature, Burstein (2003) concludes that public opinion usually affects policy decisions and that the magnitude of the effect can be substantial. Consequently, movements may seek to change public opinion with the ultimate goal of affecting policy.

Public reactions to grievances are also important given that the popularity of an issue could affect the distribution of social rewards and disincentives faced by people contemplating activism. A popular issue could result in increased encouragement and decreased discouragement by social ties, reducing barriers to actual participation (Klandermans and Oegema 1987; McAdam and Paulsen 1993). Similarly, broad support for an issue could bolster an individual's confidence that a critical mass or threshold will be achieved to attain campaign goals, making participation more attractive (Chwe 1999; Marwell and Oliver 1993).

Because attitudinal support offers a multitude of advantages to social movement actors, I evaluate people's perceptions of grievances, independent of their willingness to take specific 
actions for a campaign. I ask questions that tap into perceptions about the mobilizing strength of the grievance, such as whether it is viewed as morally wrong, unjust, an important issue, or something that causes a significant amount of hardship. I also examine how people view the reactions of others to both the grievance and related campaign to assess potential social incentive or threshold effects.

In addition to inspiring sympathetic support, some grievances may be better equipped than others to rouse emotional responses. In turn, emotions can be important for propelling individuals into action. Anger, in particular, can be a strong mobilizing emotion and is seen as a powerful component in injustice frames (Gamson 1992). Nepstad and Smith (2001) found that moral outrage was a driving force in the Central American peace movement of the 1980s, and Jasper's (1997) work on moral shocks emphasized the importance of outrage in motivating action. While anger is perhaps the most studied emotion in mobilization, other emotions can encourage movement support. Herzog and Golden (2009) found that animal rights activists scored higher on disgust sensitivities than people not aligned with animalrelated causes, raising the possibility that disgust can motivate activism. Compassion is a moral emotion that makes people want to alleviate the suffering of others and thus is connected to prosocial action (Haidt 2003). Jasper (1998) described compassion as an emotion of interest for protest, as concern for others can foster a desire to help them. Similarly, grief or sadness about an issue may also indicate concern for the plight of those experiencing a grievance and can be linked to a desire to help those affected.

Social movements may use emotional reactions to more successfully recruit adherents and garner resources to achieve their goals. It is possible that grievances viewed as more unjust and immoral are better able to provoke emotions, which could affect motivators for activism. Alternatively, some scholars argue that emotion and intuition occur first to affect moral judgments, and this then informs reasoning (Haidt 2001). This suggests there could be a feedback effect where emotional reactions lead people to view a grievance as worse and in need of addressing. For both these reasons, I evaluate how the nature of grievances can affect emotional reactions.

Last, taking action is essential to sustaining social movements, and I examine how grievances affect people's willingness to engage in activism. Beyerlein and Hipp (2006) model participation as a two-stage mobilization process that first involves a willingness to participate in protest and then conversion of that willingness into actual participation. Following the first step of their model, this study assesses participants' willingness to engage in a variety of forms of activism, including those considered to be low-cost (e.g., signing a petition) and high-cost (e.g., attending a disruptive protest).

Thus, there are many ways that the content of grievances could potentially affect social movements - from sympathetic support to emotional reactions to taking action for a campaign. The question remains, however: do grievances differ in their ability to generate such outcomes? In the next section, I utilize research on judgment and decision-making biases and related concepts to develop specific hypotheses about how the content of grievances might provide advantages or disadvantages to social movements.

\section{THE POWER OF GRIEVANCES: LOSS AVERSION AND OMISSION BIAS}

Extant social movement literature has already suggested several ways that grievances might differ in their public appeal and mobilizing abilities. This study focuses on potential effects emerging from biases in how individuals process information and interpret events. Psychology has identified dozens of cognitive and attributional biases that could potentially affect mobilization. In this paper, I focus on the implications of two biases-loss aversion and omission bias - in affecting attitudes, emotions, and actions towards grievances and campaigns. 
Both of these judgment and decision-making biases have effects that make them particularly well suited for affecting mobilization processes.

\section{Loss Aversion: Implications for Social Movements}

Loss aversion has been described as one of the most important concepts in behavioral economics (Blavatskyy 2011). In their seminal work on prospect theory, Kahneman and Tversky (1979) assessed how people make decisions under conditions of risk and thereby developed a value function that indicates that people have risk-seeking preferences for gambles involving losses and risk-averse preferences for gambles involving gains. Further, people value losses and gains differently, with the aggravation experienced from losing money appearing to be greater than the pleasure associated with gaining the same amount. Tversky and Kahneman (1981) also found that framing a scenario to address a disease outbreak in terms of gains or losses induced dramatically different responses to a logically equivalent outcome. Once again, the responses showed that decision-making choices involving gains are often risk averse, while decision-making choices involving losses lead to risk taking. Essentially, with loss aversion, "losses loom larger than corresponding gains" (Tversky and Kahneman 1991: 1039). Another effect relevant to people's aversion to losses is the endowment effectthat individuals often demand more money to give up an object than they would be willing to pay to acquire it (Thaler 1980). For instance, participants given a mug and then offered money for it valued it twice as much as those simply offered the choice between receiving a mug or money (Kahneman, Knetsch, and Thaler 1990).

Loss aversion is particularly relevant to social movement research on threats and reactive mobilization, which examines how real or perceived declines in resources, status, or power can encourage mobilization and social movement activity (Martin and Dixon 2010; McVeigh 1999; Snow et al. 1998; Tilly 1978; Van Dyke and Soule 2002). Tilly (1976: 367) documented an array of historical forms of collective action, which were "all moved directly against someone who had unjustly deprived, or tried to deprive, a local population of a precious resource." Examining how people react to losses may be especially applicable to conservative movements, which often seek to preserve established orders and prevent the loss of influence and power (McVeigh 1999). Several studies on extremist conservative movements find support for the idea that losses in economic and political arenas for certain groups provide opportunities for reactive social movements to expand (McVeigh 1999, 2009; Van Dyke and Soule 2002).

Thus, existing social movement research on threats and reactive movements already indicates that losses can be a potent force in motivating people to engage in collective action. Yet, plenty of examples exist where monumental social movements sought gains, such as the women's suffrage movement and the civil rights movement. Therefore, the question remains: if stripped bare of all the other important factors that affect mobilization (such as resources and political opportunities), is there something uniquely powerful about loss-based grievances? Extant literature suggests there might be.

There are several ways that loss-based grievances might be particularly adept at cultivating collective action. At the core of loss aversion is the idea that experiencing a loss confers more pain than experiencing a gain confers pleasure. And more specifically, the pain of a loss is generally greater than the pain of a nongain (Idson, Liberman, and Higgins 2000). Because of this discrepancy, people may view loss-based grievances as stronger than grievances involving nonreceipt of a gain. This in turn could increase people's sympathy for the cause and attitudinal support for campaigns that seek to address the grievance. Similarly, the endowment effect indicates that people value something they have more than something they do not yet possess. This too could make threats to existing possessions (whether it be a physical structure such as a community center or more abstract possessions such as a freedom or right) be viewed as more detrimental than fights for items not yet attained. 
The combined effects of loss aversion and the endowment effect suggest that people will view loss-based grievances as more powerful than gain-based grievances, which has several possible consequences. First, this could increase sympathetic support for those experiencing the grievance, expanding the mobilization potential as well as tapping into the benefits of public attitudinal support. Second, if loss-based grievances are perceived as stronger than gain-based grievances, they may be more adept at evoking emotions. These emotions, such as anger or compassion, may drive people to participate in collective action. At the same time, emotional reactions to a grievance could contribute to evaluations of how negative it is and how important it is to address it. For both of these reasons, I evaluate whether losses and gains produce different emotional responses. Third, since people tend to believe that others hold the same opinions as they do-yet another cognitive bias termed the false consensus effect (Ross, Green, and House 1977) — people may perceive broader support for rectifying loss-based grievances. In turn, believing that others will agree with or take action to address a grievance increases the perceived amount of resources available to a movement, which can affect opinions about the likelihood of campaign success (Oberschall 1994).

Because people dislike experiencing losses, they are more willing to take risks to avoid losses than they are to acquire gains. Collective action can be risky, which might make losses a better motivator for engaging in risk-taking behavior, such as attending a protest. Even in situations of low risk, people may be willing to incur the extra costs that activism entails to avoid experiencing unpleasant losses. This incentive, in combination with motivations generated by the strength of loss-based grievances, can make it more likely that people will be willing to take action for a campaign to address a loss.

Because of the extra incentives that losses may provide in fostering collective action, I posit the following about loss-based and gain-based grievances (all else being equal):

$\mathrm{LH}_{1}$ : A loss-based grievance will be perceived as stronger than a gain-based grievance.

$\mathrm{LH}_{2}$ : A loss-based grievance will elicit more emotions than a gain-based grievance.

$\mathrm{LH}_{3}$ : A loss-based grievance will increase willingness to engage in collective action relative to a gain-based grievance.

$\mathrm{LH}_{4}$ : People will perceive broader public support for a loss-based campaign relative to a gain-based campaign.

$\mathrm{LH}_{5}$ : A loss-based campaign will be viewed as more likely to succeed in attaining its goals than a gain-based campaign.

\section{Omission Bias and Support for Collective Action}

Omission bias suggests that social movements will be more successful when the target has committed an act of commission (carrying out an action) versus an act of omission (not carrying out an action). Omission bias is a preference for harms caused by omission over equal or lesser harm caused by acts (Baron and Ritov 2004). Even when intentions, motivations, and consequences are held constant, there is a tendency to view acts of commission as more immoral and more causal than similar acts of omission (Spranca et al. 1991). An example of this is found in human euthanasia, in which active acts of euthanasia, such as through lethal drug injections, are more controversial than passive acts of euthanasia, such as orders not to resuscitate. People perceive physicians engaging in active euthanasia as more responsible for patients' deaths, as more immoral and less humane, and as acting outside the standards of the medical profession than physicians engaging in passive euthanasia (Sugarman 1986). The effects of omission bias have also been found in the antivaccine move- 
ment, where parents are reluctant to incur perceived potential harms by administering a vaccine yet take risks with dangers that could result from not vaccinating (Asch et al. 1994). This reflects the underlying logic of omission bias, where there is "a greater willingness to accept harm from omission, the default, than harms from action" (Baron and Ritov 2004).

There are several mechanisms that suggest why commissions might motivate collective action more effectively than omissions. One key distinction is that because commissions involve direct causation, rather than the indirect causation of omissions, it is easier to attribute responsibility and blame to people who act than to those who do not (Hauser, Tonnaer, and Cima 2009; Spranca et al. 1991). Being able to assign blame is an essential task in framing processes (Benford and Snow 2000). Further, the ability to attribute specific blame for a grievance increases the likelihood of protest (Javeline 2003). Attribution of blame can focus collective action on a concrete target. This, in turn, aids aggrieved actors by limiting the scope and focus of collective action, which reduces costs and increases perceptions that protest can be effective (Javeline 2003).

Blame can also be essential to generating emotions. Jasper (1998) posits that the types of threats that are more difficult to direct blame toward (e.g., natural disasters) tend to generate emotions like grief and resignation, while those that represent clear targets are more likely to generate outrage. Additionally, specification of blame can aid mobilization by generating "villains," and such "[d]emonization fuels powerful emotions for social movements, such as hatred, fear, anger, suspicion, and indignation" (Jasper 1998: 412).

Since commissions are often viewed as morally worse than omissions (Cushman, Young, and Hauser 2006; Spranca et al. 1991), this suggests that people will view grievances that result from commissions as more immoral and unjust than those resulting from omissions. The combination of stronger grievances, increased attributions of blame, and heightened emotional responses to commissions may ultimately increase willingness to participate in collective action to redress such grievances. These mechanisms could also lead people to view others as being more sympathetic toward and supportive of commission-based campaigns. Additionally, being able to focus blame could augment feelings that protest will be more effective and increase beliefs that such campaigns might ultimately be more successful.

Given that commissions can potentially provide advantages to social movements, I hypothesize the following about commission-based and omission-based grievances (all else being equal):

$\mathrm{OH}_{1}$ : A commission-based grievance will be perceived as stronger than an omissionbased grievance.

$\mathrm{OH}_{2}$ : A commission-based grievance will result in higher levels of blame attributed to perpetrators when compared to an omission-based grievance.

$\mathrm{OH}_{3}$ : A commission-based grievance will evoke more emotions than an omissionbased grievance.

$\mathrm{OH}_{4}$ : A commission-based grievance will increase willingness to engage in collective action relative to an omission-based grievance.

$\mathrm{OH}_{5}$ : People will perceive broader public support for a commission-based campaign relative to an omission-based campaign.

$\mathrm{OH}_{6}$ : A commission-based campaign will be more perceived as more likely to succeed in attaining its goals than an omission-based campaign. 


\section{STUDY 1: LOSS AVERSION}

\section{Participants}

Participants were recruited from undergraduate sociology classes at a large public university in the southwestern U.S. for the opportunity to earn money. The vignettes were distributed to 120 participants, with 60 receiving the loss frame and 60 receiving the gain frame. Four cases were dropped due to missing data resulting in a total $\mathrm{N}$ of 116 (58 loss frame, 58 gain frame). There were 85 females and 31 males. The vast majority of the participants were aged 18-25 (111 participants) with the remaining five participants aged 26-35 years.

\section{Procedure and Materials}

The experiment took place in classrooms where participants were handed a vignette/ questionnaire packet with compensation attached $(\$ 3.00)$. Vignettes were randomly ordered to maintain random assignment. The vignette and questionnaire took approximately fifteen minutes to complete, and participants were not allowed to interact with one another. I used a between-subjects design, such that each participant read only one vignette (loss version or gain version).

The vignette began with these instructions: "Imagine that you attend this university and have just been sent this email by a student activist group. Please read it below and answer the questions that follow." The loss-based grievance then read: "Currently, students have the ability to vote in town hall style community meetings to directly affect university decisions. The university administration wants to take away our vote. Please join us in our fight to prevent the loss of these important voting rights." The gain-based grievance version read: "Currently, students do not have the ability to vote in town hall style community meetings to directly affect university decisions. The university administration does not want to give us a vote. Please join us in our fight to gain these important voting rights." Participants then answered a series of questions that asked about the strength of the grievance, emotional reactions to the grievance, and perceptions of others' reactions to the grievance.

The next section was prefaced with these instructions: "For this next section of the questionnaire, imagine that a member of the student activist group has approached you to take action to (gain students a vote/prevent students from losing their vote) in community meetings." This was followed by questions asking about personal willingness to participate in actions for the campaign as well as perceptions of others' willingness to participate in the campaign. The questionnaire then concluded with demographic and control questions, and the final page welcomed participants to write in additional comments, such as reactions to the campaign, further explanation of answer choices, or general comments on the survey.

\section{Dependent Measures}

Strength of grievance addressed the underlying act, that students would either lose their vote or not gain a vote in town hall style meetings to affect university decisions, and then evaluated the strength of this issue through four items. The first question asked about the level of hardship that would be experienced by students if the act occurred (answer choices ranged from 1 none at all to 7 very high levels); the second asked if the act was morally right or wrong ( 1 very right to 7 very wrong); the third asked whether the act was just or unjust (1 very just to 7 very unjust); and the fourth asked the participant if they viewed this issue as an unimportant or an important problem (1 very unimportant to 7 very important).

Emotions were assessed by a series of questions asking participants the extent to which, if at all, they would feel anger, disgust, sadness, and compassion for students if the university (did not give students a/took away the students') vote in community meetings, with each emotion listed separately (1 not at all to 7 very high levels). 
Others' reactions were evaluated through two sets of questions. The first set captured how the participant viewed others' opinions of the grievance. For this an index was created that summed and then took the average of two questions (Cronbach's $\alpha=.80$ ) asking the participant whether the average person would think that students (not gaining a vote/losing a vote) in the university community meetings was (a) morally right or wrong (1 very right to 7 very wrong) and (b) just or unjust (1 very just to 7 very unjust). The second set assessed respondents' perceptions of others' willingness to participate in the campaign. An index was created by summing and averaging five questions (Cronbach's $\alpha=.81$ ) that asked respondents how willing they thought other students at the university would be to take action to (get the university to give students a/stop the university from taking away students') vote, with the following actions listed: sign a petition; donate money; attend a peaceful protest; recruit other people to take action for the issue; and attend a disruptive protest, like occupying a street without permission (each action had answer choices ranging from 1 very unwilling to 7 very willing).

Campaign support was evaluated through a series of questions. General support was gauged by asking participants to what extent, if at all, they would support this activist campaign to either get the university to give students a vote or to stop the university from taking away students' vote in community meetings ( 1 not at all to 7 very high levels). Willingness to participate in the campaign was measured by asking how willing respondents would be to take actions for this campaign, with the following actions listed: sign a petition; donate money; recruit other people to take action; attend a peaceful protest; and attend a disruptive protest, like occupying a street without permission (each action had answer choices ranging from 1 very unwilling to 7 very willing).

Campaign success was measured by asking participants whether they believed the activist student group would be unsuccessful or successful in (getting the university to give students a/stopping the university from taking away students') vote (1 most likely unsuccessful to 7 most likely successful).

\section{Control Measures}

To ensure random assignment across the loss and gain groups, I included several control questions to check that relevant traits were distributed equally across the two groups. The first was self-identified political orientation (ranging from 1 very liberal to 7 very conservative); participants averaged 3.5, which is between somewhat liberal (3) and moderate (4). There was not a significant difference across the loss group $(M=3.48 ; S D=1.23)$ and the gain group $(M$ $=3.55 ; S D=1.57)$ in regard to political orientation $(t(114)=-.265 ; p=.792)$. The second set of control questions referred to participants' general willingness to engage in activism. Participants were asked to "Think of an actual cause, one that you really care about and is important to you. How willing would you be to do the following actions for this cause:" with the options of: sign a petition; donate money; attend a peaceful protest; recruit other people to take action for the issue; and attend a disruptive protest, like occupying a street without permission ( 1 very unwilling to 7 very willing). I created an index that summed and averaged the five measures (Cronbach's $\alpha=.81$ ). There was not a significant difference across the loss group $(M=5.17 ; S D=1.22)$ and the gain group $(M=5.01 ; S D=1.18)$ in regard to willingness to engage in activism for an ideal cause $(t(114)=.70 ; p=.487)$.

\section{Analysis and Results}

To evaluate the effects of loss and gain grievances on the dependent variables, I used a series of independent samples $t$-tests to assess whether the mean ratings on measures for the group receiving the gain-based grievance were significantly different from the means on those measures for the group receiving the loss-based grievance. My hypotheses are unidirectional, making one-tailed tests the appropriate analytical strategy. I also calculated Cohen's $d$ to 
evaluate the effect size, which is the distance between group means in standard deviations. As a standardized measure of group differences, this can speak to the magnitude of the effect. In general, a Cohen's $d$ of .20 indicates a small/weak effect, .50 signals a medium/moderate effect, and .80 suggests a large/strong effect (Cohen 1988).

Because I conducted multiple statistical tests, I increased the odds that one of my findings was statistically significant by chance. There is some debate about the best way to compensate for multiple hypothesis testing, with some scholars arguing that corrective methods such as the Bonferroni correction are too conservative, leading to type II errors in which true discoveries are falsely rejected (Nakagawa 2004; Narum 2006; Perneger 1998). I follow Perneger's (1998) suggestion of reporting the unadjusted $p$-values such that readers can make their own determinations.

The results from Study 1 indicate support for the loss and gain grievance hypotheses. There were significant differences in how participants reacted to loss-based and gain-based grievances, and most of these differences constituted a medium effect size. The largest effects in the study pertained to perceptions of injustice and immorality, as well as the emotional reactions of anger and disgust.

Table 1: Means by Loss or Gain for Reactions to the Grievance and Campaign

\begin{tabular}{|c|c|c|c|c|c|c|c|}
\hline & \multicolumn{2}{|c|}{ Gain Grievance } & \multicolumn{2}{|c|}{ Loss Grievance } & \multirow{2}{*}{$\begin{array}{c}t \\
(\mathrm{df}=114)\end{array}$} & \multirow{2}{*}{$\begin{array}{c}p \\
\text { (one-tailed) }\end{array}$} & \multirow[t]{2}{*}{ Cohen's d } \\
\hline & Mean & SD & Mean & $\mathrm{SD}$ & & & \\
\hline \multicolumn{8}{|l|}{ Strength of Grievance } \\
\hline Wrong & 5.28 & 1.23 & 6.02 & 1.05 & 3.5 & $<.001$ & 0.655 \\
\hline Unjust & 5.45 & 1.11 & 6.03 & 0.878 & 3.15 & 0.001 & 0.591 \\
\hline Important & 5.05 & 1.18 & 5.5 & 1.26 & 1.98 & 0.025 & 0.371 \\
\hline Hardship & 4.48 & 1.26 & 4.69 & 1.3 & 0.87 & 0.193 & 0.163 \\
\hline \multicolumn{8}{|l|}{ Emotions } \\
\hline Anger & 3.53 & 1.52 & 4.48 & 1.5 & 3.38 & $<.001$ & 0.632 \\
\hline Disgust & 3.07 & 1.52 & 4.03 & 1.6 & 3.33 & $<.001$ & 0.624 \\
\hline Sadness & 2.91 & 1.68 & 3.6 & 1.8 & 2.14 & 0.018 & 0.4 \\
\hline Compassion & 3.98 & 1.65 & 4.5 & 1.55 & 1.74 & 0.042 & 0.326 \\
\hline \multicolumn{8}{|l|}{ Campaign Support } \\
\hline Support & 3.88 & 1.43 & 4.14 & 1.32 & 1.01 & 0.156 & 0.19 \\
\hline Petition & 5.28 & 1.57 & 5.84 & 1.21 & 2.19 & 0.015 & 0.41 \\
\hline Donation & 3.09 & 1.61 & 3.81 & 1.44 & 2.55 & 0.006 & 0.477 \\
\hline Recruit & 3.5 & 1.53 & 4.03 & 1.63 & 1.82 & 0.036 & 0.341 \\
\hline Peaceful Protest & 4.1 & 1.59 & 3.97 & 1.56 & -0.473 & 0.319 & -0.089 \\
\hline Disruptive Protest & 2.31 & 1.57 & 2.84 & 1.88 & 1.66 & 0.05 & 0.311 \\
\hline \multicolumn{8}{|l|}{ Others' Reactions } \\
\hline Perceptions & 5.1 & 0.83 & 5.72 & 0.918 & 3.87 & $<.001$ & 0.725 \\
\hline Willing to Participate & 3.95 & 1.09 & 4.32 & 1.04 & 1.88 & 0.031 & 0.352 \\
\hline \multicolumn{8}{|l|}{ Campaign Success } \\
\hline Success & 4.59 & 1.19 & 4.71 & 1.26 & 0.532 & 0.298 & 0.1 \\
\hline
\end{tabular}


Results upheld the first hypothesis, that a loss-based grievance will be perceived as stronger than a gain-based grievance. The loss-based grievance was seen as significantly more immoral and unjust than the gain-based grievance. Participants who received the loss-based vignette viewed the grievance as "wrong" and "unjust," while those receiving the gain-based vignette tended to rate the grievance as "somewhat wrong" and "somewhat unjust." Participants also ranked the loss-based grievance as a significantly more important problem than the gain-based grievance, but there was not a significant difference in the amount of perceived hardship.

Results also affirmed the second hypothesis, that loss-based grievances would elicit stronger emotional responses than gain-based grievances. The loss-based grievance produced significantly higher levels of anger, sadness, disgust, and compassion. While a gain tended to evoke "low levels" of these emotions, a loss tended to rouse "moderate levels" of these emotions.

Participants were not limited to stronger attitudinal and emotional effects from losses over gains; they were also more willing to take action for campaigns seeking to address a loss, supporting the third hypothesis. This was particularly true for low-cost forms of activism, with participants significantly more willing to sign a petition, donate money, and recruit others for a loss than a gain. Participants were not more likely to engage in peaceful protest for a loss-based grievance. Both groups were unwilling to attend disruptive protest, reflecting a general reluctance to engage in risky tactics, but respondents were significantly more unwilling to attend disruptive protest for the gain-based grievance.

The findings also confirmed the fourth hypothesis, that participants would interpret broader public support for losses over gains. Participants believed that other people would view the loss-based grievance as more unjust and immoral, and would be more willing to participate in campaigns to prevent the loss-based grievance from occurring. However, the fifth hypothesis was not supported, with participants not ranking the likelihood of success as significantly higher for the loss-based campaign.

\section{Discussion}

The results from Study 1 indicate support for the idea that there is something unique about loss-based grievances that increases perceptions of injustice and encourages more interest in activism than similar gain-based grievances. Consequently, campaigns that center on a loss may experience benefits over those focused on a gain. Additionally, social movement actors may gain advantages by framing the grievances they work to address as losses, if it is plausible to do so.

Consistent with the ideas that losses loom larger than corresponding gains and that people value what they already own more than what they do not yet have, participants rated a lossbased grievance as constituting a more immoral, unjust, and important issue than a gain-based grievance. Participants also experienced stronger emotions in response to losses, both in terms of softer emotions like compassion and sadness, as well as mobilizing emotions like anger and disgust. In line with evidence that losses promote risk taking, results indicated that participants were more willing to participate in a campaign that sought to prevent a loss rather than secure a gain, and this included both low-risk and low-cost actions (signing a petition, donating money, and recruiting others) as well as the more risky option of attending a disruptive protest.

Participants' attitudes and willingness to act translated into broader perceptions that others would share these opinions and also act. Despite the increase in perceived public support, participants did not rank the likelihood of success as significantly higher for campaigns addressing a loss over a gain, perhaps reflecting pessimism that university administrators would listen to students in either case (as one participant noted in his comments). 
In sum, this study supports the idea that loss-based grievances may be stronger motivators of injustice evaluations and mobilization processes than similar gain-based grievances. While the vignette was hypothetical, it is possible that loss aversion is even more powerful in practice, when people are facing genuine threats to what they hold dear.

\section{STUDY 2: OMISSION BIAS}

\section{Participants}

Participants were recruited from undergraduate sociology classes at a large public university in the southwestern U.S. for the opportunity to earn money. The vignettes were distributed to 120 participants ( 60 commission frame, 60 omission frame). Five cases were dropped due to missing data resulting in a total $\mathrm{N}$ of 115 (59 omission frame, 56 commission frame). There were 82 females and 33 males. Almost all participants were aged 18-25 (113 participants), with two participants aged 31-35 years.

\section{Procedure and Materials}

The experiment took place in classrooms where participants were handed a vignette/ questionnaire packet with compensation attached $(\$ 3.00)$. Vignettes were randomly ordered to maintain random assignment. The vignette and questionnaire took approximately fifteen minutes to complete, and participants were not allowed to interact with one another. I used a between-subjects design, such that each participant read only one vignette (commission version or omission version). The vignette was introduced with these written instructions: "Imagine that you are a member of this community and have just been sent this email by an activist group. Please read it below and answer the questions that follow." The commissionbased grievance version stated: "We are a group of concerned community members. Every year dogs suffer because people who no longer want pets abandon them, and the dogs wander the streets. We want to end this practice and are lobbying for stricter laws and punishments regarding this issue." The omission-based grievance version read: "We are a group of concerned community members. Every year dogs suffer because people who no longer want pets do not repair fences, and the dogs wander the streets. We want to end this practice and are lobbying for stricter laws and punishments regarding this issue." It is important to note that the vignettes posit equal pet owners' intentions (that they no longer want pets) and have equal outcomes (that dogs suffer and wander the streets). Thus, the perpetrators are motivated by the same goals and equally negative outcomes for dogs occur in each version. This allows the focus to be on the nature of the act itself, whether the grievance occurred due to a commission (directly abandoned dogs) verses an omission (did not repair fences resulting in abandoned dogs).

Participants then answered a series of questions that asked about emotional reactions to the grievance, the strength of the grievance, perceptions of others' reactions to the grievance, and attributions of blame. Next, the vignette turned to reactions to the campaign and stated: "For this next section of the questionnaire, imagine that an activist has approached you to take action on this issue of punishing people who no longer want dogs as pets and (abandon them/do not repair fences), resulting in dogs ending up on the street." This was followed by questions asking about support for the campaign, personal willingness to participate in actions for the campaign, and then perceptions of others' willingness to participate in the campaign. The final section of the survey asked several demographic and control questions and concluded with an opportunity to write in additional comments. 
Almost all dependent measures were identical to Study 1. One exception is that the question on level of hardship was replaced with a question on attribution of blame that asked how much these pet owners were to blame for the dogs being on the street (1 not at all to 7 completely). Also, in Study 2 the answer scales were changed for the question asking whether the act was unjust ( 1 not at all unjust to 7 extremely unjust) and for the question that asked if the act was morally wrong ( 1 not at all wrong to 7 extremely wrong). Finally, in Study 2 two changes were made to questions asking about perceptions of others' reactions. Others' opinions was assessed through a single question asking whether the participant thought the average person would view the issue as an unimportant or an important problem (1 very unimportant to 7 very important). The index for perceptions of others' willingness to participate in the campaign included a question that asked respondents if they thought other community members would support the activist campaign (1 not at all to 7 very high levels) in addition to the other five measures of others' willingness to take action for the campaign described in Study 1 (Cronbach's $\alpha=.83$ ).

The control questions were the same as those in Study 1 asking about self-identified political orientation and willingness to engage in activism (willingness to engage in activism index for Study 2 had a Cronbach's $\alpha=.79)$. There was not a significant difference between the commission group $(M=3.45 ; S D=1.37)$ and the omission group $(M=3.71 ; S D=1.63)$ in regard to political orientation $(t(113)=-.909 ; p=.366)$. There was also not a significant difference across the commission group $(M=5.25 ; S D=1.08)$ and the omission group $(M=$ 5.01; $S D=1.10)$ in regard to willingness to engage in activism for an ideal cause $(t(113)=$ $1.19 ; p=.238)$. An additional control question was asked in Study 2 that assessed the extent to which participants cared about animal welfare and asked if, in general, they viewed the well being of dogs as important or unimportant compared to other issues. On average, participants indicated it was "somewhat important" with no significant difference between the omission group $(M=5.12 ; S D=1.34)$ and the commission group $(M=5.13 ; S D=1.22)$ on this measure $(t(113)=.027 ; p=.979)$.

\section{Analysis and Results}

I employed a series of independent samples $t$-tests to assess whether the mean ratings on measures for the group receiving the commission-based grievance are significantly different from the means on those measures for the group receiving the omission-based grievance. I used one-tailed tests, calculated Cohen's $d$ to evaluate the effect size, and did not adjust $p$ values for multiple hypothesis testing.

The results from Study 2 indicate that commission-based and omission-based grievances are perceived differently, with the commission-based grievance being viewed as stronger and generating higher levels of emotions. The commission-based grievance also produced greater support and willingness to take action for the campaign to redress the grievance. Most of the dependent measures in the study showed significant differences between an act of commission and an omission and suggested moderate effect sizes.

The findings support the first hypothesis that commission-based grievances will be perceived as stronger than omission-based grievances, with the commission-based grievance viewed as significantly more immoral, unjust, and important. More specifically, participants who received the commission-based vignette viewed the grievance as "highly" wrong and unjust while those receiving the omission-based vignette tended to rank the grievance as "moderately" to "somewhat highly" wrong and unjust. Both of these measures constituted strong effect sizes. Participants also ranked the commission-based grievance as a significantly more important problem than the omission-based grievance. 
Table 2: Means by Commission or Omission for Reactions to the Grievance and Campaign

\begin{tabular}{|c|c|c|c|c|c|c|c|}
\hline & \multicolumn{2}{|c|}{$\begin{array}{c}\text { Omission } \\
\text { Grievance }\end{array}$} & \multicolumn{2}{|c|}{$\begin{array}{c}\text { Commission } \\
\text { Grievance }\end{array}$} & \multirow{2}{*}{$\begin{array}{c}\mathbf{t} \\
(\mathrm{df}=113)\end{array}$} & \multirow{2}{*}{$\frac{\mathbf{p}}{\text { (one-tailed) }}$} & \multirow[t]{2}{*}{ Cohen's d } \\
\hline & Mean & $S D$ & Mean & SD & & & \\
\hline \multicolumn{8}{|l|}{ Strength of Grievance } \\
\hline Wrong & 4.8 & 1.51 & 6.05 & 0.999 & 5.3 & $<.001$ & 0.987 \\
\hline Unjust & 4.98 & 1.54 & 6.25 & 0.837 & 5.53 & $<.001$ & 1.03 \\
\hline Important & 5.03 & 1.4 & 5.55 & 1.11 & 2.2 & 0.015 & 0.413 \\
\hline \multicolumn{8}{|l|}{ Emotions } \\
\hline Anger & 3.98 & 1.79 & 4.8 & 1.7 & 2.52 & 0.007 & 0.475 \\
\hline Disgust & 3.98 & 1.75 & 5.29 & 1.59 & 4.17 & $<.001$ & 0.785 \\
\hline Sadness & 4.78 & 1.75 & 5.55 & 1.54 & 2.51 & 0.007 & 0.473 \\
\hline Compassion & 5.53 & 1.61 & 6.09 & 1.2 & 2.14 & 0.017 & 0.399 \\
\hline \multicolumn{8}{|l|}{ Attribution of Blame } \\
\hline Blame & 5.31 & 1.28 & 5.88 & 0.974 & 2.7 & 0.004 & 0.505 \\
\hline \multicolumn{8}{|l|}{ Campaign Support } \\
\hline Support & 4.27 & 1.61 & 4.73 & 1.29 & 1.69 & 0.047 & 0.319 \\
\hline Petition & 5.31 & 1.67 & 6.11 & 1.15 & 3 & 0.002 & 0.56 \\
\hline Donation & 4.09 & 1.7 & 4.88 & 1.38 & 2.75 & 0.004 & 0.515 \\
\hline Recruit & 3.78 & 1.82 & 4.29 & 1.62 & 1.57 & 0.06 & 0.296 \\
\hline Peaceful Protest & 3.68 & 1.77 & 4.27 & 1.51 & 1.92 & 0.029 & 0.362 \\
\hline Disruptive Protest & 2.44 & 1.63 & 2.84 & 1.74 & 1.27 & 0.103 & 0.239 \\
\hline \multicolumn{8}{|l|}{ Others' Reactions } \\
\hline Important & 4.42 & 1.25 & 4.66 & 1.05 & 1.1 & 0.136 & 0.207 \\
\hline Support and Action & 3.79 & 0.979 & 4.06 & 0.976 & 1.52 & 0.066 & 0.29 \\
\hline \multicolumn{8}{|l|}{ Campaign Success } \\
\hline Success & 4.1 & 1.53 & 4.84 & 1.14 & 2.94 & 0.002 & 0.55 \\
\hline
\end{tabular}

As predicted, the commission-based grievance resulted in significantly higher attributions of blame to perpetrators, supporting the second hypothesis. Participants ranked pet owners as closest to "mostly" to blame for an omission and as nearest to "almost completely" to blame for a commission.

Results upheld the third hypothesis that commission-based grievances would generate stronger emotional responses than omission-based grievances. The commission-based grievance produced significantly higher levels of anger, disgust, sadness, and compassion for dogs. Disgust, in particular, had a large effect size, with participants ranking the omission-based grievance as producing "moderate levels" of disgust and the commission-based grievance as generating "somewhat high" levels of disgust. Participants were also more willing to take action for campaigns seeking to address an act of commission over an omission, offering support for the fourth hypothesis. They were significantly more likely to support the campaign in general and to be willing to sign a petition, donate money, and participate in peaceful protest to address a commission-based grievance as compared to an omission-based grievance.

Interestingly, personal support and willingness to participate in campaigns did not translate into a belief that other community members would do so as well, although the effect did near significance. Additionally, participants did not believe that others would view the 
commission-based grievance as significantly more important. Thus, findings did not support the fifth hypothesis that perceptions of broader public support would be higher for commission-based grievances than omission-based grievances. However, results confirmed the sixth hypothesis that a commission-based campaign would be viewed as more likely to succeed in attaining its goals. Participants rated the likelihood of success of the omission-based campaign as closer to "neutral" while the commission-based campaign was rated as closer to "possibly successful."

\section{Discussion}

The findings from Study 2 indicate that commission-based grievances may be more effective than omission-based grievances in eliciting a sense of injustice and securing support for campaigns to redress the grievance. Results also show that commissions generate other condemning emotions such as anger and disgust, as well as sympathetic emotions like sadness and compassion. It is interesting that participants rated the commission as producing more compassion for dogs since the outcomes were equal - that dogs ended up on the street. This could indicate that people viewed these dogs as suffering more, not necessarily from the outcome, but from the immorality of the act.

The results support conclusions from extant literature that moral evaluations of commissions and omissions differ, although this is the first study to apply them in a social movement setting. Similarly, the direct causation of commission-based grievances did result in higher attributions of blame. The ability to direct blame, in concert with perceptions that commissions are more punishable than omissions, could have contributed to the finding that the commission-based grievance campaign was viewed as more likely to succeed. Thus, the commission/omission distinction could be one way that grievances differ in conferring advantages on social movements.

\section{GENERAL DISCUSSION}

The question posed in this research is whether the nature of grievances affects a variety of measures associated with mobilization-including attitudinal support, emotional reactions, and a willingness to take action - and results of both studies provide evidence that the nature of grievances can provide advantages or disadvantages to social movements.

There are commonalities across the studies on loss aversion and omission bias that suggest how grievances can differentially affect mobilization. Both biases are particularly effective at producing differences in evaluations of the morality and injustice of grievances. This is an important finding as injustice serves as the lifeblood fueling most movements. As Gamson (1992: 32) argued, injustice focuses on the righteous anger that puts fire in the belly and iron in the soul. An interesting set of findings across both studies is how successful both losses and commissions are in producing stronger emotional reactions. This holds true for anger, typically conceptualized as a mobilizing emotion, but the effects are equally strong, if not stronger, for the emotion of disgust, which is far less frequently examined in social movement literature. Additionally, the less frequently studied emotions of compassion and sadness are also significantly affected by these biases. Taken in concert, the perceptions of a stronger injustice coupled with higher levels of more diverse emotional reactions suggest the nature of grievances can affect both moral judgments and moral emotions. Both of these, in turn, can provide fuel for social movement mobilization.

While there are general trends across the two biases, there are also results specific to each form. For instance, the logic of loss aversion emphasizes risk taking to prevent losses and risk aversion to acquire gains, which is reflected in the results showing that people are significantly more unwilling to attend disruptive protest for gain-based grievances. There is 
not a similar effect for engaging in risky protest for commission-based grievances. Conversely, the logic of omission bias places a premium on blame attribution and the benefits that confers, including perceptions that agreement on targets and focused movement resources will make campaign success more likely. This study finds that commission-based grievances improve perceptions of campaign success, a result not found in the loss aversion study. Thus, while both biases have broad effects in regard to grievance evaluations and campaign support, there are also effects specific to the particular logic of each.

While this article investigated hypothetical campaigns, we can see elements of both loss aversion and omission bias in recent protests across the world. When the Netherlands legalized human euthanasia, which had widespread public support, thousands still turned out to protest (Osborn and Boseley 2001). In Brazil, an increase in bus and subway fares sparked massive protests that led leaders in several cities to reverse the fare hikes (Brooks 2013). In Turkey, a small peaceful demonstration opposing the destruction of Gezi Park resulted in a government crackdown that ultimately led tens of thousands of people to protest (Arsu 2013). In both Brazil and Turkey, these initial protests regarding a loss sparked larger nationwide movements about broader social and political issues.

That grievances tapping into loss aversion and omission bias affect sympathy and support for campaigns also raises interesting questions for framing appeals. Mobilizers already face difficulties in crafting frames to motivate people to avoid social dilemmas like freeriding or the efficacy problem (Vasi and Macy 2003). The results from this study also suggest that the nature of grievances may condition the effectiveness of framing appeals. Many social movements are likely to involve issues that have latitude in whether the grievance can be framed as a loss or a commission, making it relatively easy for mobilizers to use this information to their advantage. Other issues may lack such flexibility in terms of their capacity to be defined as a loss or a commission, making the nature of the grievance a constraint on framing attempts. More rigid grievances may require additional time and effort for social movement actors to successfully develop frames that draw on loss aversion and omission bias or may make it easier for countermovements and other actors to contest such frames. In this way, the raw material of a grievance can differ in the extent to which it naturally aids or hinders particular collective action frames.

Ultimately, loss aversion and omission bias are just two of many potential trends in decision making and information processing that could be used to map how the subject matter of a grievance can affect attitudes toward, and a willingness to support, specific causes. Future research could investigate the effects of other cognitive biases, as well as any cumulative or combinatorial effects that occur when grievances reflect multiple biases acting in concert. Further, while this article serves to identify one route - judgment and decision-making biasesfor how the nature of grievances might systematically benefit or hinder social movements, there are likely to be other typologies of grievances that influence mobilization processes. By investigating the ways that grievances matter, we can begin to chart how the content of the issues championed by social movements affects the ability of social movement actors to recruit new members and attract resources. This, in turn, adds a new set of variables to understanding the strength and success of social movements.

\section{NOTES}

\footnotetext{
${ }^{1}$ Although Henrich, Heine, and Norenzayan (2010) found that broad claims about human psychology and behavior derived from samples in Western, Educated, Industrialized, Rich, and Democratic (WEIRD) societies do not necessarily apply worldwide.
} 


\section{REFERENCES}

Arceneaux, Kevin. 2012. "Cognitive Biases and the Strength of Political Arguments." American Journal of Political Science 56(2): 271-85.

Arsu, Sebnem. 2013. "Development Project in Istanbul, Focus of Violent Protests, Is Stopped by Court." New York Times, July 3. Retrieved October 2013 (www.nytimes.com/2013/07/04/world/europe/ development-project-in-istanbul-focus-of-violent-protests-is-stopped-by-ourt.html?_r=1\&).

Asch, David A., Jonathan Baron, John C. Hershey, Howard Kunreuther, Jacqueline Meszaros, Ilana Ritov, and Mark Spranca. 1994. "Omission Bias and Pertussis Vaccination." Medical Decision Making 14(2): 118-123.

Baron, Jonathan, and Ilana Ritov. 2004. "Omission Bias, Individual Differences, and Normality." Organizational Behavior and Human Decision Processes 94(2): 74-85.

Benford, Robert, and David A. Snow. 2000. "Framing Processes and Social Movements: An Overview and Assessment." Annual Review of Sociology 26: 611-39.

Beyerlein, Kraig, and John R. Hipp. 2006. "A Two-Stage Model for a Two-Stage Process: How Biographical Availability Matters for Social Movement Mobilization." Mobilization 11(3): 219-40.

Blavatskyy, Pavlo. 2011. "Loss Aversion.” Economic Theory 46(1): 127-148.

Brooks, Bradley. "Brazil Officials Reverse Subway, Bus Fare Hike." The Associated Press, June 19. Retrieved October 2013 (worldnews.nbcnews.com/_news/2013/06/19/19044251-brazil-officialsreverse-subway-bus-fare-hike?lite).

Burstein, Paul. 2003. "The Impact of Public Opinion on Public Policy: A Review and an Agenda." Political Research Quarterly 56(1): 29-40.

Chwe, Michael Suk Young. 1999. "Structure and Strategy in Collective Action." American Journal of Sociology 105(1): 128-156.

Cohen, Jacob. 1988. Statistical Power Analysis for the Behavioral Sciences, $2^{\text {nd }}$ edition. Hillsdale, NJ: Lawrence Erlbaum Associates, Inc.

Cushman, Fiery, Liane Young, and Marc Hauser. 2006. "The Role of Conscious Reasoning and Intuition in Moral Judgment: Testing Three Principles of Harm." Psychological Science 17(12): 1082-89.

Fetner, Tina. 2001. "Working Anita Bryant: The Impact of Christian Anti-Gay Activism on Lesbian and Gay Movement Claims.” Social Problems 48(3): 411-28.

Gamson, William. 1992. Talking Politics. New York: Cambridge University Press.

Goodwin, Jeff, James M. Jasper, and Francesca Polletta, eds. 2001. Passionate Politics: Emotions and Social Movements. Chicago: University of Chicago Press.

Haidt, Jonathan. 2001. "The Emotional Dog and Its Rational Tail: A Social Intuitionist Approach to Moral Judgment.” Psychological Review 108(4): 814-34.

- 2003. "The Moral Emotions." Pp. 852-70 in Handbook of Affective Sciences, edited by Richard J. Davidson, Klaus R. Scherer, and H. Hill Goldsmith. Oxford: Oxford University Press.

Hardin, Garrett. 1968. "The Tragedy of the Commons.” Science 162(3859): 1243-48.

Haselton, Martie G., Daniel Nettle, and Paul W. Andrews. 2005. "The Evolution of Cognitive Bias.” Pp. 724-46 in The Handbook of Evolutionary Psychology, edited by David M. Buss. Hoboken. NJ: Wiley.

Hauser, Marc, Franca Tonnaer, and Maaike Cima. 2009. "When Moral Intuitions are Immune to the Law: A Case Study of Euthanasia and the Act-Omission Distinction in the Netherlands." Journal of Cognition and Culture 9(3): 149-169.

Henrich, Joseph, Steven J. Heine, and Ara Norenzayan. 2010. "The Weirdest People in the World?" Behavioral and Brain Sciences 33(2-3): 61-83.

Herzog, Harold A., and Lauren L. Golden. 2009. "Moral Emotions and Social Activism: The Case of Animal Rights.” Journal of Social Issues 65(3): 485-98.

Idson, Lorraine Chen, Nira Liberman, and E. Tory Higgins. 2000. "Distinguishing Gains from Nonlosses and Losses from Nongains: A Regulatory Focus Perspective on Hedonic Intensity.” Journal of Experimental Social Psychology 36(3): 252-74.

Jasper, James M. 1997. The Art of Moral Protest. Chicago: University of Chicago Press. . 1998. "The Emotions of Protest: Affective and Reactive Emotions in and Around Social Movements." Sociological Forum 13(3): 397-424.

Javeline, Debra. 2003. "The Role of Blame in Collective Action; Evidence from Russia." American Political Science Review 97(1): 107-121.

Kahneman, Daniel, and Amos Tversky. 1979. "Prospect Theory: An Analysis of Decision under Risk." Econometrica 47(2): 263-92. 
Kahneman, Daniel, Jack L. Knetsch, and Richard H. Thaler. 1990. "Experimental Tests of the Endowment Effect and the Coase Theorem." The Journal of Political Economy 98(6): 1325-48.

Klandermans, Burt, and Dirk Oegema. 1987. "Potentials, Networks, Motivations, and Barriers: Steps Towards Participation in Social Movements." American Sociological Review 52(4): 519-31.

Kollock, Peter. 1998. "Social Dilemmas: The Anatomy of Cooperation." Annual Review of Sociology 24: 184-214.

Kornhauser, William. 1959. The Politics of Mass Society. New York: Free Press.

Luker, Kristin. 1984. Abortion and the Politics of Motherhood. Berkeley: University of California Press.

Martin, Andrew, and Marc Dixon. 2010. "Changing to Win? Threat, Resistance, and the Role of Unions in Strikes, 1984-2002." American Journal of Sociology 116(1): 93-129.

Marwell, Gerald, and Pamela Oliver. 1993. The Critical Mass in Collective Action. New York: Cambridge University Press.

McAdam, Doug, and Ronnelle Paulsen. 1993. "Specifying the Relationship between Social Ties and Activism." American Journal of Sociology 99(3): 640-67.

McCarthy, John D., and Mayer N. Zald. 1977. "Resource Mobilization and Social Movements: A Partial Theory." American Journal of Sociology 82(6): 1212-41.

McVeigh, Rory. 1999. "Structural Incentives for Conservative Mobilization: Power Devaluation and the Rise of the Ku Klux Klan, 1915-1925.” Social Forces 77(4): 1461-96.

- 2009. The Rise of the Ku Klux Klan: Right-Wing Movements and National Politics. Minneapolis: University of Minnesota Press.

Nakagawa, Shinichi. 2004. "A Farewell to Bonferroni: The Problems of Low Statistical Power and Publication Bias." Behavioral Ecology 15(6): 1044-1045.

Narum, Shawn. 2006. "Beyond Bonferroni: Less Conservative Analyses for Conservation Genetics." Conservation Genetics 7(5): 783-87.

Nepstad, Sharon Erickson, and Christian Smith. 2001. "The Social Structure of Moral Outrage in Recruitment to the U.S. Central America Peace Movement.” Pp. 158-174 in Passionate Politics, edited by Jeff Goodwin, James Jasper, and Francesca Polletta. Chicago: University of Chicago Press.

Oberschall, Anthony. 1994. "Rational Choice in Collective Protests." Rationality and Society 6(1): 79-100.

Olson, Mancur. 1965. The Logic of Collective Action. Cambridge, MA: Harvard University Press.

Osborn, Andrew, and Sarah Boseley. 2001. "Dutch Pass Euthanasia Bill." The Guardian, April 10. Retrieved October 2013 (www.theguardian.com/world/2001/apr/11/andrewosborn. sarahboseley).

Perneger, Thomas V. 1998. "What's Wrong with Bonferroni Adjustments." British Medical Journal 316(7139): 1236-38.

Ross, Lee, David Greene, and Pamela House. 1977. "The False Consensus Effect: An Egocentric Bias in Social Perception and Attribution Processes.” Journal of Experimental Social Psychology 13(3): 279-301.

Smelser, Neil J. 1962. Theory of Collective Behavior. New York: Free Press.

Snow, David A., and Robert D. Benford. 1988. "Ideology, Frame Resonance, and Participant Mobilization." International Social Movement Research 1(1): 197-218.

Snow, David A., Daniel M. Cress, Liam Downey, and Andrew W. Jones. 1998. "Disrupting the 'Quotidian': Reconceptualizing the Relationship between Breakdown and the Emergence of Collective Action." Mobilization 3(1): 1-22.

Spranca, Mark, Elisa Minsk, and Jonathan Baron. 1991. "Omission and Commission in Judgment and Choice.” Journal of Experimental Social Psychology 27(1): 76-105.

Sugarman, David B. 1986. "Active Versus Passive Euthanasia: An Attributional Analysis." Journal of Applied Social Psychology 16(1): 60-76.

Thaler, Richard. 1980. “Toward a Positive Theory of Consumer Choice." Journal of Economic Behavior and Organization 1(1): 39-60.

Tilly, Charles. 1976. "Major Forms of Collective Action in Western Europe 1500-1975." Theory and Society 3(3): 365-75.

-1978. From Mobilization to Revolution. Reading, MA: Addison-Wesley.

Tversky, Amos, and Daniel Kahneman. 1981. "The Framing of Decisions and the Psychology of Choice." Science 211(4481): 453-58.

- 1991. "Loss Aversion in Riskless Choice: A Reference-Dependent Model." The Quarterly Journal of Economics 106(4): 1039-61.

Van Dyke, Nella, and Sarah A. Soule. 2002. "Structural Social Change and the Mobilizing Effect of Threat: Explaining Levels of Patriot and Militia Organizing in the United States." Social Problems 49(4): 497-520. 
Vasi, Ion Bogdan, and Michael Macy. 2003. "The Mobilizer's Dilemma: Crisis, Empowerment, and Collective Action." Social Forces 81(3): 979-98.

Walsh, Edward J. 1981. "Resource Mobilization and Citizen Protest in Communities around Three Mile Island." Social Problems 29(1): 1-21. 